\title{
Methicillin resistance of Staphylococcus species among health care and nonhealth care workers undergoing cataract surgery
}

This article was published in the following Dove Press journal:

Clinical Ophthalmology

9 December 2010

Number of times this article has been viewed

\section{Randall Olson' \\ Eric Donnenfeld ${ }^{2}$ \\ Frank A Bucci Jr ${ }^{3}$ \\ Francis W Price $\mathrm{Jr}^{4}$ \\ Michael Raizman ${ }^{5}$ \\ Kerry Solomon ${ }^{6}$ \\ Uday Devgan ${ }^{7}$ \\ William Trattler ${ }^{8}$ \\ Steven Dell ${ }^{9}$ \\ R Bruce Wallace ${ }^{10}$ \\ Michelle Callegan"I \\ Heather Brown"I \\ Peter J McDonnell ${ }^{12}$ \\ Taryn Conway'3 \\ Rhett M Schiffman ${ }^{13}$ \\ David A Hollander ${ }^{13}$}

'The John A. Moran Eye Center, University of Utah, Salt Lake City, UT, USA;

${ }^{2}$ Ophthalmic Consultants of Long Island and Connecticut, Rockville Centre, NY, USA; ${ }^{3}$ Bucci Laser Vision Institute, Wilkes-Barre, PA, USA; ${ }^{4}$ Price Vision

Group, Indianapolis, IN, USA; ${ }^{5}$ Ophthalmic Consultants of Boston, Boston, MA, USA; ${ }^{6}$ Department of Ophthalmology, Medical University of South Carolina, Charleston, SC, USA; ${ }^{7}$ Maloney Vision Institute, Los Angeles, CA, USA; ${ }^{8}$ Center for Excellence in Eye Care, Miami, FL, USA; ${ }^{9}$ Dell Laser Consultants, Austin, TX, USA; ${ }^{10}$ Wallace Eye Surgery, Laser and Surgery Center, Alexandria, LA, USA; ' 'Department of Ophthalmology, University of Oklahoma Health Sciences Center, Dean A. McGee Eye Institute, Oklahoma City, OK, USA; ${ }^{12}$ Wilmer Eye Institute, the Johns Hopkins University School of Medicine, Baltimore, MD, USA; ${ }^{13}$ Allergan Inc., Irvine, CA, USA

Correspondence: Randall Olson The John A Moran Eye Center, University of Utah, 65 Mario Capecchi Drive, Salt Lake City, UT 84I 32, USA

Tel + I 80I 5856622

Fax + I 80I 58I 3357

Email randallj.olson@hsc.utah.edu
Purpose: The purpose of this study is to characterize the bacterial flora of the ocular and periocular surface in cataract surgery patients and to determine the prevalence of methicillin resistance among staphylococcal isolates obtained from health care workers (HCWs) and non-HCWs.

Methods: In this prospective, multicenter, case series study, eyelid and conjunctival cultures were obtained from the nonoperative eye of 399 consecutive cataract patients on the day of surgery prior to application of topical anesthetics, antibiotics, or antiseptics. Speciation and susceptibility testing were performed at the Dean A. McGee Eye Institute. Logistic regression was utilized to evaluate whether any factors were significant in predicting the presence of methicillin-resistant staphylococcal isolates.

Results: Staphylococcus epidermidis (62.9\%), followed by S. aureus (14.0\%), was the most frequently isolated organism. Methicillin-resistant $S$. epidermidis accounted for $47.1 \%(178 / 378)$ of $S$. epidermidis isolates, and methicillin-resistant $S$. aureus accounted for $29.5 \%(26 / 88)$ of S. aureus isolates. Methicillin-resistant staphylococcal isolates were found in 157 of $399(39.3 \%)$ patients, the majority $(89.2 \%)$ of whom were non-HCWs. The likelihood of being colonized with methicillin-resistant organisms increased with age (odds ratio [OR], 1.27; 95\% confidence interval $[\mathrm{CI}]: 1.02-1.58 ; P=0.04)$ but decreased with diabetes (OR, $0.51 ; 95 \% \mathrm{CI}: 0.29-0.89$; $P=0.02)$. Being a $\mathrm{HCW}(\mathrm{OR}, 1.25 ; 95 \% \mathrm{CI}: 0.61-2.58 ; P=0.54)$ was not a risk factor for colonization with methicillin-resistant organisms.

Conclusion: Patients without exposure to health care environments are as likely as HCWs to be colonized with methicillin-resistant organisms. Increasing methicillin resistance with age may partially explain the increased risk of endophthalmitis reported with older age.

Keywords: age, bacterial flora, cataract surgery, methicillin resistance, ocular and periocular surface, Staphylococci

\section{Introduction}

The endogenous ocular and periocular bacteria flora serve as the predominant source of organisms leading to postoperative infection. ${ }^{1,2}$ In recent years, the incidence of endophthalmitis following cataract extraction has ranged from $0.015 \%$ to $0.25 \%{ }^{3-8}$ Despite aggressive intervention, approximately half of all patients who develop acute postoperative endophthalmitis fail to achieve final visual acuity of 20/40 or better., ${ }^{9,10}$

Microorganisms from the ocular and periocular surface may enter the anterior chamber during cataract extraction, with reported rates of anterior chamber contamination as high as $43 \% .{ }^{11-13}$ In addition, laboratory models of human cadaveric eyes have demonstrated fluid flow across clear corneal wounds, with the potential for bacterial entry in the early postoperative period explaining increased rates of endophthalmitis associated with clear corneal incisions. ${ }^{14,15}$ The Endophthalmitis Vitrectomy Study 
demonstrated that the vast majority of cases of postcataract endophthalmitis arise secondary to Gram-positive organisms, including Staphylococcus epidermidis and S. aureus. ${ }^{14}$ Although a similar spectrum of bacteria has been observed in subsequent studies of endophthalmitis, ${ }^{9,15,16}$ recent reports from tertiary care centers suggest changes in the antibiotic susceptibility patterns of these isolates with most causative organisms now being methicillin resistant. ${ }^{16,17}$

Methicillin-resistant $S$. aureus (MRSA), first reported in the $1960 \mathrm{~s},{ }^{18,19}$ has now become one of the most common and devastating causes of bacterial infections in hospitals and intensive care units. ${ }^{20}$ In recent years, community-acquired MRSA has also emerged in otherwise healthy individuals without prior exposure to health care facilities. ${ }^{21-23}$ Of particular concern to ophthalmic surgeons is the rising number of reports of ocular infections secondary to both MRSA and methicillin-resistant S. epidermidis (MRSE).,17,24-31 In addition to resistance to $\beta$-lactam antimicrobials, both nosocomial and community-acquired strains of MRSA and MRSE are becoming increasingly multidrug resistant. ${ }^{3,29,32,33}$

Effective prophylactic strategies for reducing the risk of postoperative endophthalmitis, such as preoperative povidone-iodine application and the use of perioperative topical antibiotics, are specifically designed to reduce the bacterial flora on the ocular and periocular surface. Evaluating the bacteria present on the conjunctiva and eyelids and their sensitivities provides important information in determining a rational approach to the selection of antibiotics for surgical prophylaxis and treatment of ocular infections. This study was undertaken to characterize the bacteria present on the ocular and periocular surface in patients undergoing cataract extraction. In addition, the study was designed to determine the prevalence of methicillin resistance among staphylococcal isolates cultured from individuals working in the health care industry and nonhealth care workers (non-HCWs) to determine if this remains a valid determinant of risk.

\section{Methods}

A prospective, multicentered study was conducted at 10 sites in the United States between December 2007 and August 2008. Eyelid and conjunctival cultures were obtained from the nonoperative eye in 399 patients undergoing elective cataract surgery. The patients represented a consecutive series of patients from a single surgeon at each site who satisfied inclusion criteria. Cultures were performed on the day of surgery prior to the application of any topical anesthetics, antibiotics, or antiseptics. This study was initiated following approval by the Institutional Review Board at each of 10 study sites and was performed in compliance with the principles outlined in the Declaration of Helsinki and Health Insurance Portability and Accountability Act regulations. All patients who participated provided written informed consent prior to the initiation of study-related procedures. The trial is registered with the identifier NCT00621933 at http://www. clinicaltrials.gov.

Patient eligibility was determined at a prior screening visit. Patients aged at least 50 years scheduled for cataract extraction were eligible for the study. Primary exclusion criteria included the use of any topical ocular or periocular antibiotics, antiseptics, or lid scrubs within 7 days of cataract surgery; the use of artificial tears or contact lenses on the day of surgery; or history of any ocular infection within the prior 3 months. At screening, a questionnaire was administered in which the subjects were asked whether they were employed in a health care facility or directly cared for a person in a long-term care facility. Those who answered yes to this question were categorized as HCWs for purposes of analysis. An additional screening question was whether the subject had an immediate family member employed in a health care setting.

Two cultures were obtained on each patient using the BD CultureSwab ${ }^{\circledR}$ MaxV(+) Transport System (Becton, Dickinson and Company, Franklin Lakes, NJ). The superior eyelid was swabbed at the lash margin, followed by a swab of the inferior tarsal conjunctiva without touching the eyelid or lashes. Each unit is composed of a sterile peel pouch, containing a rayon-tipped swab applicator for collection, and a tube, containing transport medium, into which the swab applicator is placed following sampling. Samples were shipped overnight on the day of collection to a central laboratory at the University of Oklahoma Health Sciences Center, Dean A. McGee Eye Institute, for speciation and susceptibility testing.

\section{Speciation and susceptibility testing}

Each swab of collected material was streaked for isolation on $5 \%$ tryptic soy agar containing 5\% sheep blood agar (VWR International Ltd., West Chester, PA). Isolated colonies were cultured in brain-heart infusion media for $18 \mathrm{~h}$, and sterile glycerol was added to a final concentration of $15 \%$ for preparation of freezer stocks. Gram stains were performed by routine methods on all bacterial colonies. Gram-negative bacteria were speciated by the $\mathrm{BBL}^{\circledR}$ Enterotube ${ }^{\mathrm{TM}} \mathrm{II}$ system (Becton, Dickinson and Company) following manufacturer 
instructions. Briefly, the needle of the system was touched to an isolated colony and inserted into the Enterotube. Enterotubes were incubated overnight at $37^{\circ} \mathrm{C}$. The positivity of colorimetric changes was scored and matched to the Enterotube database in order to speciate each Gram-negative isolate.

Gram-positive bacteria were tested for the presence of catalase using hydrogen peroxide $(30 \%)$ to separate Staphylococcus species from other Gram-positive bacteria. Staphylococcus species were identified biochemically via colorimetric reactions using the API ${ }^{\mathrm{TM}}$ staph kit (bioMérieux, Inc., Durham, NC). Staphylococci were cultured in cationadjusted Müeller-Hinton broth $+2 \% \mathrm{NaCl}$ (CA-MHB, VWR) overnight at $37^{\circ} \mathrm{C}$. Suspensions were diluted in CA-MHB to a turbidity visually equivalent to that of a $0.5 \mathrm{McF}$ arland standard. Diluted suspensions were added to the API staph kit according to manufacturer specifications. API strips were incubated overnight at $37^{\circ} \mathrm{C}$. The colorimetric changes were scored and matched to the API database in order to speciate each Staphylococcal isolate.

Following speciation, Staphylococcus species were tested for susceptibility to oxacillin (OX) by the Etest ${ }^{\circledR}$ (bioMérieux, Inc.). By convention, oxacillin resistance is synonymous with resistance to methicillin. A suspension of the test strain equal to the visual turbidity of $0.5 \mathrm{McFarland}$ standard was prepared and swabbed onto a 100-mm-diameter plate containing 10-15 mL of cation-adjusted Müeller-Hinton agar with $2 \%$ $\mathrm{NaCl}$. The oxacillin-coated test strips were placed on each plate in accordance with the manufacturer's instructions. Oxacillin concentrations on each strip ranged from 0.016 to $256 \mu \mathrm{g} / \mathrm{mL}$. The minimum inhibitory concentrations (MICs) were interpreted after 18-24 h of incubation in ambient air at $37^{\circ} \mathrm{C}$. The MICs were compared to the oxacillin MIC breakpoints using the breakpoints defined by the Clinical Laboratory Standards Institute (CLSI), and the bacteria were categorized as susceptible or resistant. For $S$. aureus and S. lugdunensis, the oxacillin MIC breakpoints were $\leq 2 \mu \mathrm{g} / \mathrm{mL}$ (sensitive) and $\geq 4 \mu \mathrm{g} / \mathrm{mL}$ (resistant). For coagulase-negative Staphylococci other than S. lugdunensis, the oxacillin MIC breakpoints were $\leq 0.25 \mu \mathrm{g} / \mathrm{mL}$ (sensitive) and $\geq 0.5 \mu \mathrm{g} / \mathrm{mL}$ (resistant). The lowest drug concentration that inhibited $90 \%$ of strains tested was recorded as the $\mathrm{MIC}_{90}$. Oxacillin testing was not performed if the species failed to grow out of stock.

\section{Statistical analysis}

Multivariate logistic regression with forward stepwise selection was performed to evaluate the associations of the binary nominal dependent variable 'presence of methicillin-resistant Staphylococcus' with the continuous or categorical independent variables of age (by decade), race, status as a HCW, relative of a $\mathrm{HCW}$, and history of diabetes mellitus or glaucoma. Ninety-five percent confidence intervals ( $95 \%$ CIs) and odds ratios (ORs) were presented. All $P$ values were two-sided and were considered statistically significant when the values were $<0.05$. The significant variables were modeled alone and in combination against the dependent variable, and the goodness of fit of the model was evaluated using the Hosmer and Lemeshow $r^{2}$ test. All analyses were carried out using SAS (version 9.1;SAS Institute Inc., Cary, NC).

\section{Results}

Baseline demographics of the 399 cataract surgery patients enrolled in this study are shown in Table 1. Of the 399 patients, $38(9.5 \%)$ worked within the health care industry and were classified as HCWs. Fifteen of the HCWs and 68 of the non-HCWs also had an immediate family member employed in the health care industry.

Cultures were positive in $80.5 \%(321 / 399)$ of the eyelid samples and in 57.4\% (229/399) of the conjunctival samples obtained from the nonoperative eye at the time of cataract surgery. Bacterial growth of more than one strain or species was seen in $18.7 \%(60 / 321)$ of the eyes with positive eyelid cultures and in $10.0 \%(23 / 229)$ of the eyes with positive conjunctival cultures. The vast majority of the organisms isolated

Table I Baseline patient demographics of 399 cataract surgery patients

\begin{tabular}{ll}
\hline & Number (\%) \\
\hline $\begin{array}{l}\text { Gender } \\
\text { Female }\end{array}$ & $224(56.1)$ \\
Age, years & \\
Mean (SD) & $69.5(10.2)$ \\
Median (range $)$ & $70(24-97)$ \\
Race, $n$ (\%) & \\
Caucasian & $347(87.3)$ \\
African American & $15(3.6)$ \\
Hispanic/Latino & $27(6.6)$ \\
Asian/Pacific Islander & $6(1.5)$ \\
Other & $4(1.0)$ \\
Comorbidities, $n$ (\%) & \\
Glaucoma & $35(8.8)$ \\
Diabetes & $83(20.9)$ \\
Glaucoma and diabetes & $10(2.5)$ \\
Health care facility exposure & \\
Health care worker (HCW) & $38(9.5)$ \\
Family member of a health care worker & $83(20.8)$ \\
\hline
\end{tabular}

Note: ${ }^{\text {SSix }}$ patients were protocol violations based on age criterion alone. 
from both the eyelids and conjunctiva were Gram-positive species (Figure 1). S. epidermidis was the most frequently isolated organism, accounting for $61.8 \%$ (243/393) of the eyelid isolates and $64.5 \%(165 / 256)$ of the conjunctival isolates, followed by $S$. aureus, which accounted for $15.3 \%$ (60/393) of the eyelid isolates and $12.1 \%(31 / 256)$ of the conjunctival isolates.

The oxacillin (methicillin) susceptibility patterns of 539 staphylococcal isolates (331 eyelid and 208 conjunctival species) are shown in Figure 2. Overall, oxacillin (methicillin) resistance was seen in 222 of the 539 (41.2\%) isolates. A similar percentage of oxacillin (methicillin) resistance was seen in the staphylococcal isolates obtained from both the lids (42.9\%) and the conjunctiva (38.5\%). Of 378 S. epidermidis isolates tested from the lid and conjunctiva, $178(47.1 \%)$ were oxacillin (methicillin) resistant and categorized as MRSE. Of the 88 S. aureus isolates tested, 26 (29.5\%) were oxacillin (methicillin) resistant and categorized as MRSA. The distribution of oxacillin (methicillin) resistance based on the specific site locations is shown in Table 2.
Overall, oxacillin (methicillin)-resistant staphylococcal isolates of either the lid or conjunctiva were obtained from 157 of the $399(39.3 \%)$ patients. The majority (89.2\%) of these patients with oxacillin (methicillin)-resistant isolates were categorized as non-HCWs. Based on HCW status, the percentage of staphylococcal isolates categorized as oxacillin (methicillin) resistant was similar in the HCWs (40.7\%) and non-HCWs (41.2\%). The MICs for the $26 \mathrm{MRSA}$ isolates and the $178 \mathrm{MRSE}$ isolates are listed in Table 3, separated by HCW status.

Table 4 shows the associations of various baseline characteristics and potential risk factors with the presence of methicillin-resistant staphylococcal isolates on the ocular or periocular surface. On logistic regression, only age $(P=0.04)$ and diabetes mellitus $(P=0.02)$ were statistically significant factors influencing ocular and periocular surface colonization. While increasing age (OR, 1.27 per decade; 95\% CI: 1.02-1.58) beginning at the sixth decade was associated with an increase in ocular surface colonization with methicillin-resistant organisms, the diagnosis of diabetes

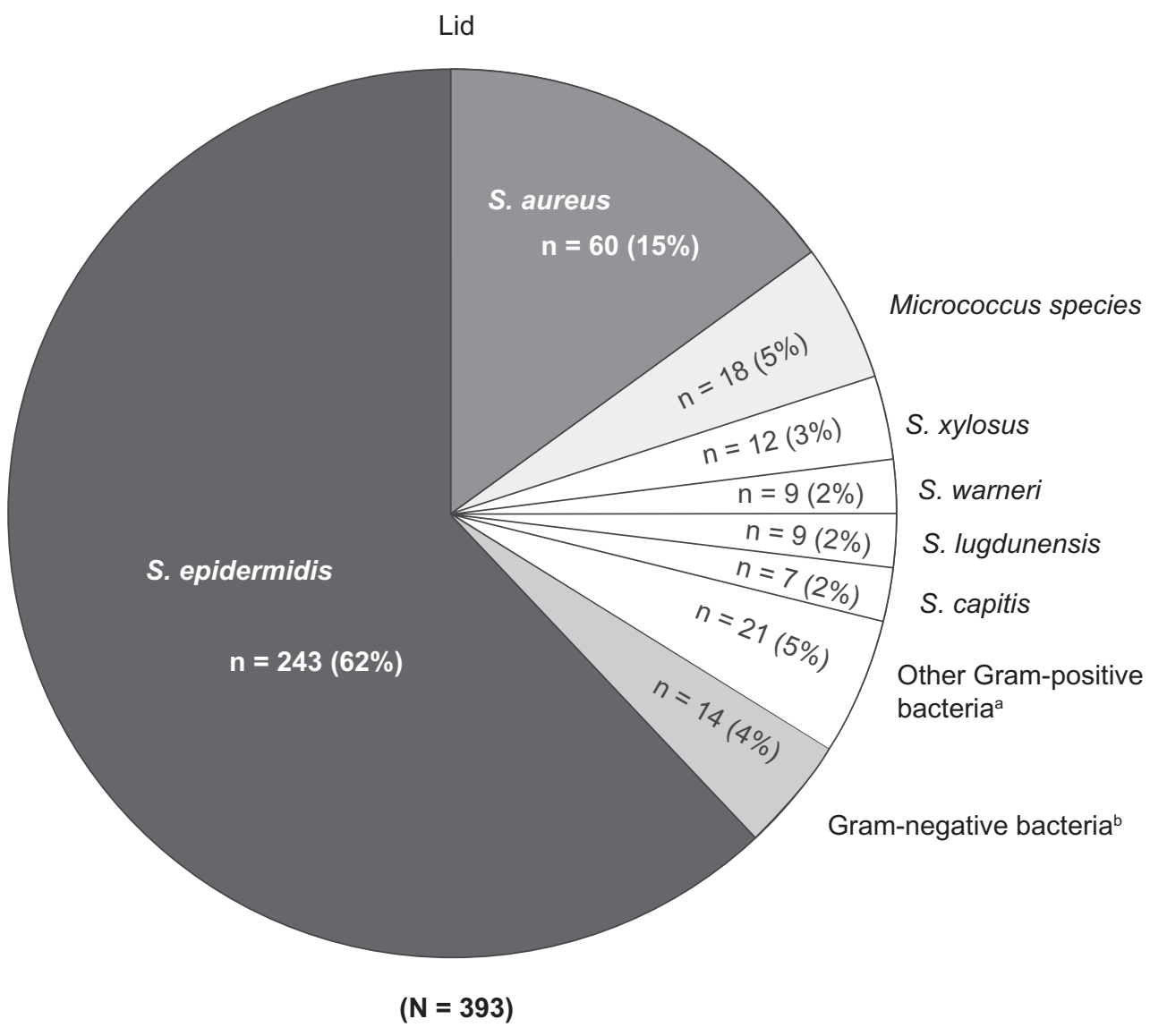

Figure I A Bacterial species on the lids and conjunctiva of cataract surgery patients.

Notes: alncluded S. hominis $(n=6 ; 1.5 \%)$, S. saprophyticus $(n=3 ; 0.8 \%)$, Streptococcus species $(n=3 ; 0.8 \%)$, S. sciuri $(n=2 ; 0.5 \%)$, S. lentus $(n=2 ; 0.5 \%)$, S haemolyticus $(n=2 ; 0.5 \%)$, S. caprae $(n=2 ; 0.5 \%)$, and S. cohnii spp urealyticus $(n=1 ; 0.3 \%)$; ' Included Enterobacter agglomerans $(n=5 ; 1.3 \%)$, Serratia marcescens $(n=2 ; 0.5 \%)$, Kiebsiella ozaenae $(n=2 ; 0.5 \%)$, Enterobacter aerogenes $(\mathrm{n}=1 ; 0.3 \%)$, Escherichia coli $(\mathrm{n}=1 ; 0.3 \%)$, Acinetobacter Iwoffii $(\mathrm{n}=1 ; 0.3 \%)$, Kocuria varianslrosea $(\mathrm{n}=1 ; 0.3 \%)$, and Shigella $(\mathrm{n}=1 ; 0.3 \%)$. 


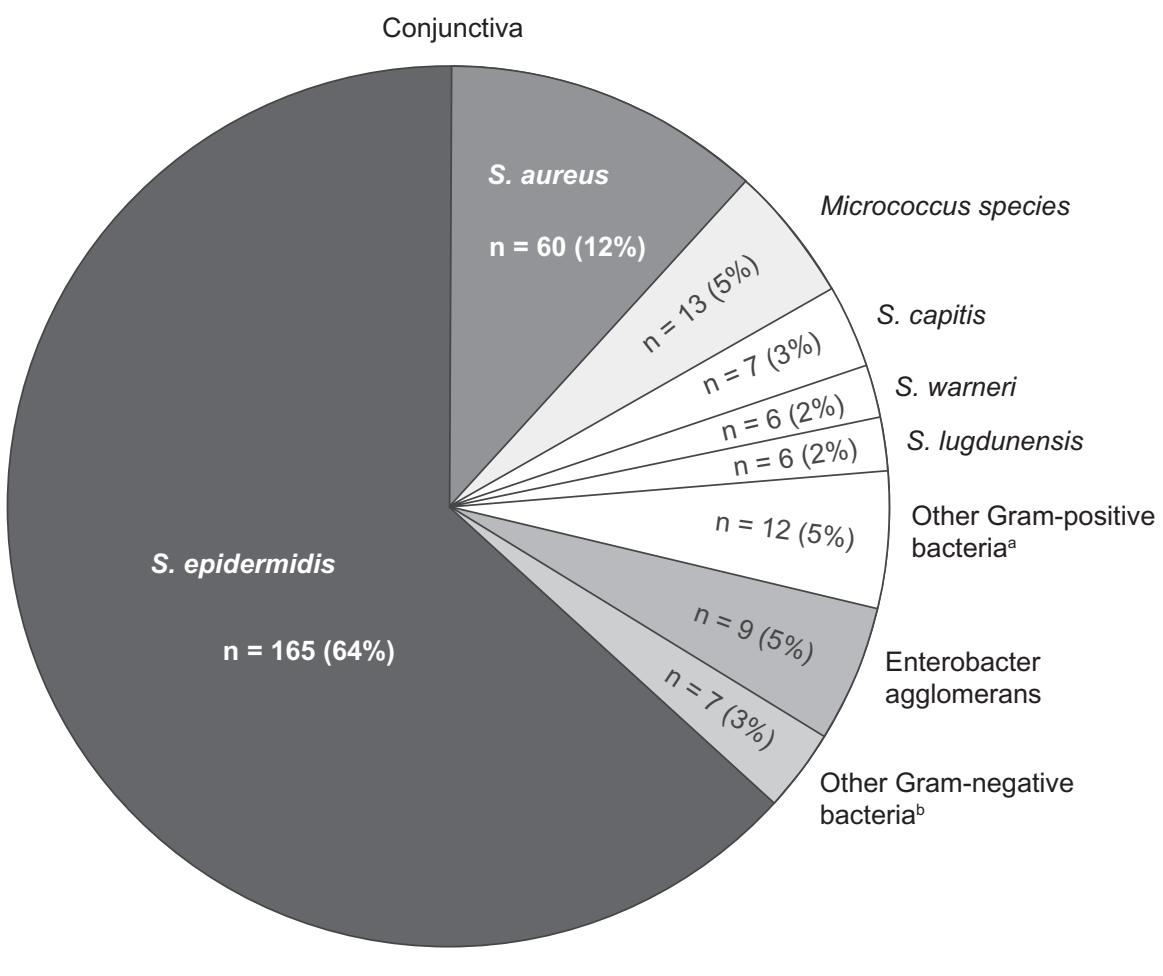

$(\mathrm{N}=256)$

Figure I B Bacterial species on the lids and conjunctiva of cataract surgery patients.

Notes: alncluded S. hominis $(n=4 ; 1.6 \%)$, S. caprae $(n=3 ; 1.2 \%)$, S. haemolyticus $(n=3 ; 1.2 \%)$, S. xylosus $(n=2 ; 0.8 \%)$; b Included Kocuria varians/rosea $(n=2 ; 0.8 \%)$, Kocuria kristinae $(n=1 ; 0.4 \%)$, Enterobacter aerogenes $(n=1 ; 0.4 \%)$, Enterobacter cloacae $(n=1 ; 0.4 \%)$, Klebsiella pneumoniae $(n=1 ; 0.4 \%)$, Serratia marcescens $(n=1 ; 0.3 \%)$.

mellitus (OR, 0.51; 95\% CI: 0.29-0.89) was associated with a lower prevalence of methicillin-resistant staphylococcal isolates. A detailed listing of the percentage of patients with methicillin-resistant staphylococcal isolates by decade is shown in Table 5.

\section{Discussion}

The present study was designed to characterize the surface flora of patients undergoing cataract surgery and to assess the prevalence of methicillin-resistant staphylococcal isolates present on the ocular and periocular surface.

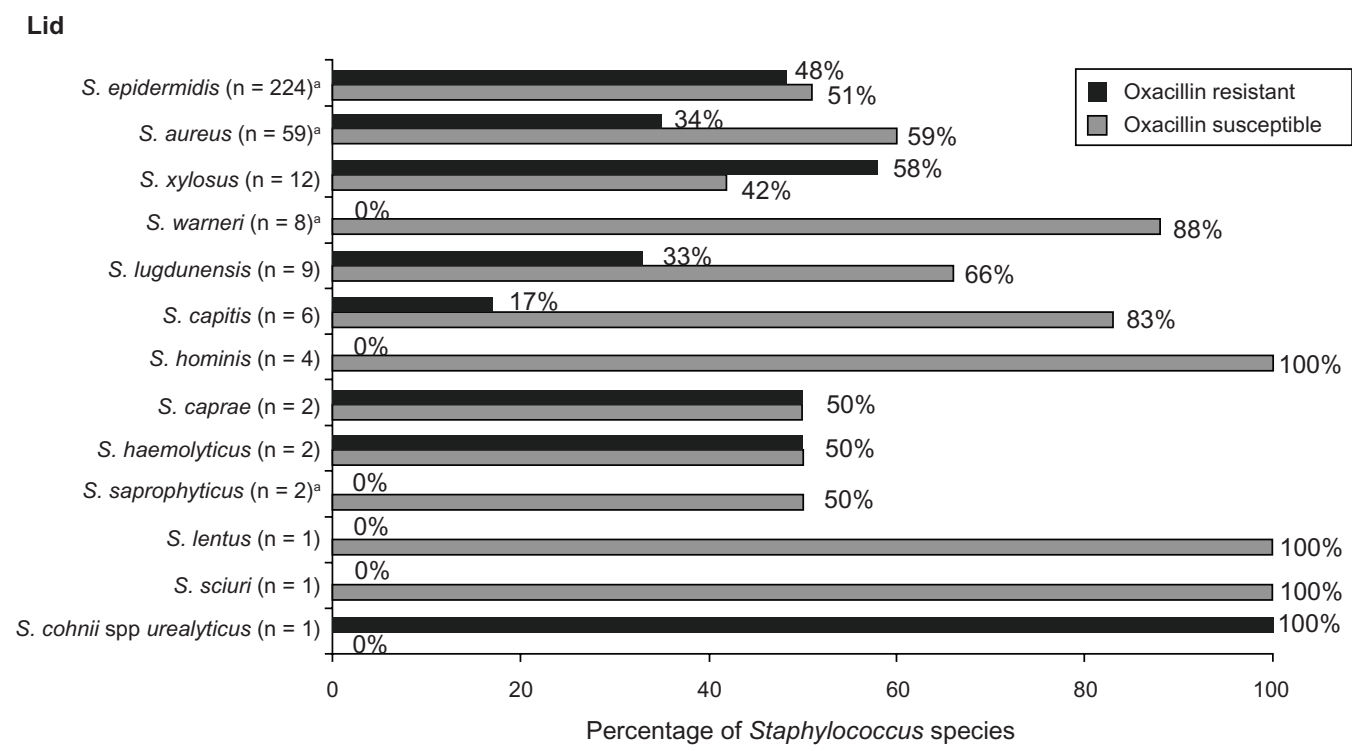

Figure 2A Oxacillin (methicillin) susceptibility of lid and conjunctival Staphylococcus species.

Notes: a Four (7\%) S. aureus isolates, 2 (I.O\%) S. epidermis isolates, I (50\%) S. saprophyticus isolate, and I (I2\%) S. warneri isolate were intermediately resistant to oxacillin. 


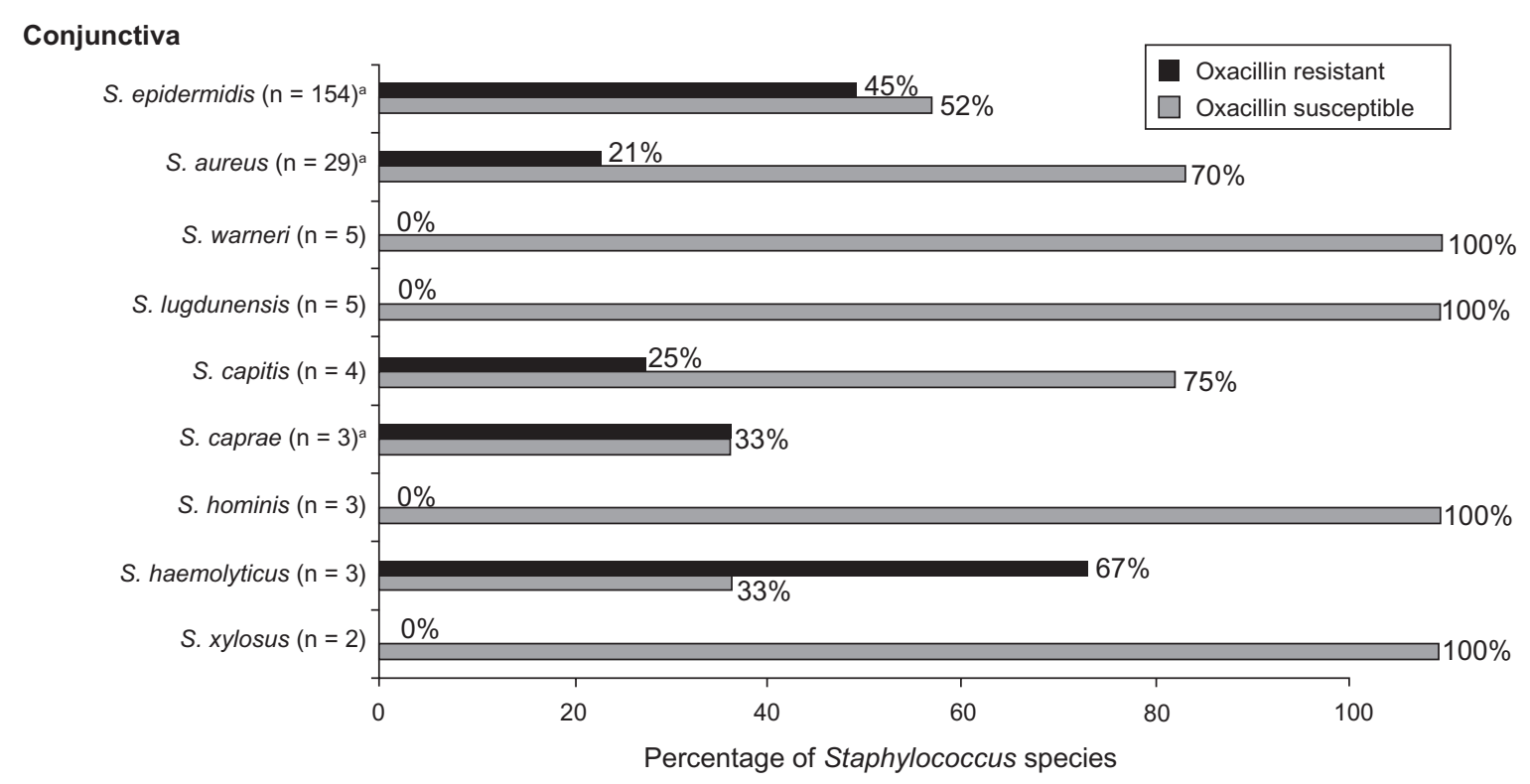

Figure 2B Oxacillin (methicillin) susceptibility of lid and conjunctival Staphylococcus species.

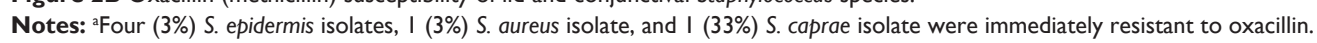

Resistance to methicillin and other $\beta$-lactams originates from the production of an altered penicillin-binding protein (PBP2a) encoded by the mecA gene. The term 'methicillin resistance' is still used to describe staphylococcal isolates resistant to $\beta$-lactam antibiotics, despite the fact that oxacillin has replaced methicillin for purposes of laboratory testing. While methicillin-resistant infections were originally associated with hospitalized patients, community-acquired strains arose in the 1990s in patients without prior health care-related exposures and are becoming increasingly common.

It is well established that postoperative endophthalmitis most commonly develops from ocular entry of endogenous bacteria from the ocular and periocular surface. ${ }^{1,2}$ Consistent with prior reports, the vast majority of isolates identified in the present study were Gram-positive organisms, specifically S. epidermidis and $S$. aureus. ${ }^{34-37}$ More importantly, methicillin resistance was detected in $47.1 \%$ of the $S$. epidermidis isolates and $29.5 \%$ of the $S$. aureus isolates. This high rate of methicillin resistance in lid and conjunctival isolates is consistent with the rising rates of ocular infections reported secondary to MRSA and MRSE.

Although MRSA typically represented $<5 \%$ of all S. aureus ocular infections in the 1990s, ${ }^{27,29}$ The Surveillance Network data set revealed that the proportion of MRSA among $S$. aureus-related serious ocular infections had climbed to $41.6 \%$ by $2005 .{ }^{24}$ Furthermore, Deramo et al reported MRSA in 6 of 33 (18.2\%) culture-positive cases of endophthalmitis, ${ }^{17}$ and Miller et al noted that MRSE accounted for 52 out of $86(60.5 \%)$ cases of S. epidermidis

Table 2 Distribution of oxacillin (methicillin)-resistant Staphylococcus isolates by study sites

\begin{tabular}{llllll}
\hline & \multicolumn{2}{l}{ Lid Staphylococcus } & & \multicolumn{2}{l}{ Conjunctival Staphylococcus } \\
\cline { 2 - 3 } \cline { 5 - 6 } & No. of isolates & No. of resistant isolates (\%) & & No. of isolates & No. of resistant isolates (\%) \\
\hline Alexandria, LA & 25 & $13(52.0)$ & $6(66.7)$ & 15 & $9(60.0)$ \\
Austin, TX & 9 & $17(50.0)$ & $16(42.1)$ & 9 & $3(33.3)$ \\
Boston, MA & 34 & $15(36.6)$ & $13(35.1)$ & 19 & $8(42.1)$ \\
Charleston, SC & 38 & $9(36.0)$ & 31 & $7(22.6)$ \\
Indianapolis, IN & 41 & $17(37.8)$ & 25 & $6(24.0)$ \\
Long Island, NY & 37 & $21(60.0)$ & 21 & $7(33.3)$ \\
Los Angeles, CA & 25 & $15(35.7)$ & 7 & $2(28.6)$ \\
Miami, FL & 45 & $142(42.9)$ & 21 & $9(42.9)$ \\
Salt Lake City, UT & 35 & 42 & 331 & 28 & $16(50.0)$ \\
Wilkes-Barre, PA & & & & 208 & $13(46.4)$ \\
Total & & &
\end{tabular}


Table 3 Distribution of oxacillin (methicillin)-resistant Staphylococcal isolates based on status as a health care or nonhealth care worker

\begin{tabular}{llll}
\hline & $\begin{array}{l}\text { Nonhealth care } \\
\text { workers }\end{array}$ & $\begin{array}{l}\text { Health care } \\
\text { workers }\end{array}$ & Total \\
\hline $\begin{array}{l}\text { MRSA } \\
\text { No. of isolates }\end{array}$ & 25 & 1 & 26 \\
$\begin{array}{l}\text { Oxacillin MIC }(\mu \mathrm{g} / \mathrm{mL}) \\
\quad \text { Median }\end{array}$ & $>256$ & $4^{\mathrm{a}}$ & $>256$ \\
$\quad$ MIC & & $4^{\mathrm{a}}$ & $>256$ \\
$\quad$ Range & $16->256$ & $4-4$ & $4->256$ \\
MRSE & 159 & 19 & 178 \\
$\quad$ No. of isolates & & & \\
Oxacillin MIC $(\mu \mathrm{g} / \mathrm{mL})$ & 96 & 192 & 96 \\
$\quad \begin{array}{l}\text { Median } \\
\text { MIC }\end{array}$ & $>256$ & $>256$ & $>256$ \\
$\quad$ Range & $0.5->256$ & $0.5->256$ & $0.5->256$ \\
\hline
\end{tabular}

Note: ${ }^{2}$ This number corresponds to an $\mathrm{MIC}_{100}$ based on a single MRSA isolate tested from a health care worker.

Abbreviations: MRSA, oxacillin (methicillin)-resistant S. aureus; MIC, minimum inhibitory concentration; MRSE, oxacillin (methicillin)-resistant $S$. epidermidis; median, the middle MIC value in the ordered array of MIC values.

endophthalmitis. ${ }^{10}$ From recent reports, it has also become evident that MRSA and MRSE ocular infections are no longer confined to $\mathrm{HCW}$ s and patients with exposure to long-term care facilities. $^{30}$

In the United States, the frequency of both systemic and ocular methicillin-resistant staphylococcal infections in community settings is on the rise. ${ }^{25,38,39}$ In the present study, $89 \%$ of patients colonized with methicillin-resistant staphylococcal isolates were non-HCWs. More importantly, the percentage of staphylococcal isolates found to be methicillin-resistant was similar between HCWs and non-HCWS (40.7\% versus $41.2 \%$, respectively). Genetically confirmed strains of community-acquired methicillin-resistant Staphylococcus (USA 300 clone), which are most commonly associated with skin and soft-tissue infections, have now been reported in the ophthalmic literature in association with lid abscesses, orbital cellulitis, endophthalmitis, panophthalmitis, and superior ophthalmic vein thrombosis. ${ }^{40}$

Table 4 Effect of potential factors on the prevalence of methicillinresistant Staphylococcal ocular surface isolates

\begin{tabular}{lll}
\hline Factor & OR $(\mathbf{9 5 \%} \mathbf{C I})$ & P value \\
\hline Health care worker & $1.25(0.61-2.58)$ & 0.54 \\
Relative of health care worker & $0.73(0.43-1.26)$ & 0.26 \\
Age $^{\mathrm{a}}$ & $\mathrm{I} .27(1.02-1.58)$ & 0.04 \\
Diabetes mellitus & $0.5 \mathrm{I}(0.29-0.89)$ & 0.02 \\
Glaucoma & $\mathrm{I} .44(0.69-3.00)$ & 0.33
\end{tabular}

Note: age was evaluated in the model based on incremental increases by decade from the sixth through the tenth decade.

Abbreviations: $\mathrm{OR}$, odds ratio; $\mathrm{Cl}$, confidence interval.
Table $\mathbf{5}$ Correlation of patient age and rate of methicillin-resistant ocular and periocular surface flora

\begin{tabular}{lll}
\hline Age group (yrs) & No. of patients & $\begin{array}{l}\text { Percentage of patients } \\
\text { with methicillin-resistant } \\
\text { surface flora }\end{array}$ \\
\hline$<50$ & $6^{\mathrm{a}}$ & $0 \%$ \\
$50-59$ & 61 & $29.5 \%$ \\
$60-69$ & 126 & $33.3 \%$ \\
$70-79$ & 138 & $34.0 \%$ \\
$80-89$ & 60 & $48.3 \%$ \\
$90-99$ & 8 & $50.0 \%$ \\
\hline
\end{tabular}

In the present study, age $(P=0.04)$ was found to be a significant risk factor contributing to increased rates of methicillin resistance. This increase in ocular surface colonization with resistant bacteria in adults may result from greater exposure to antibiotics, changes in meibomian gland secretions, an increased likelihood of lacrimal duct obstruction, cumulative episodes of contact with health care settings, or a weakened immune response. ${ }^{41-45}$ This rise in the rate of colonization with methicillin-resistant species was particularly dramatic in patients aged 80 years and older. Higher prevalence of methicillin resistance with increasing age may partially explain the findings of several recent population-based studies in which older age was associated with a greater risk for endophthalmitis. ${ }^{8,46}$ Relative to methicillin-sensitive staphylococcal species, MRSA and MRSE are less likely to be eradicated with typical prophylaxis regimens and may lead to infection upon contamination with even a small inoculum. ${ }^{47}$

In contrast to prior reports in which diabetes, often insulin-dependent diabetes, has been identified as a risk factor for both MRSA colonization as well as infections, ${ }^{48-52}$ patients with diabetes in the current study were less likely to be colonized with resistant organisms. One possible explanation may be the increased importance of hygiene and skin care in diabetics due to their greater risk of infection in general. Alternatively, this finding may have occurred due to the fact that this was a patient self-reported diagnosis or as a result of our classification of both insulin-dependent and noninsulindependent diabetic patients within a single category.

Understanding the type of bacteria present on the ocular surface allows ophthalmic surgeons to devise strategies to reduce the surface flora more effectively. Although the strongest evidence supports the preoperative application of povidone-iodine as an endophthalmitis prophylaxis regimen, ${ }^{3,53}$ multiple studies have demonstrated enhanced bacterial surface eradication with the use of preoperative topical antibiotics in addition to povidone-iodine. ${ }^{54,55}$ As a result of 
their broad-spectrum activity, fluoroquinolones (FQs) are currently the topical antibiotics most commonly used in the United States in the perioperative setting. The potency of FQs against MRSA and MRSE isolates is often compared based on in vitro MICs of their active agents and in relation to serum CLSI standards developed for systemic administration. ${ }^{10,56}$ However, these tests may not accurately account for the potentially higher antibiotic concentrations achieved with topical dosing on the ocular surface that may eradicate some 'resistant' organisms. ${ }^{54,55}$ In addition, these tests may fail to reflect enhanced antibiotic activity achieved with the formulations prepared for ophthalmic use, including the presence of preservatives such as benzalkonium chloride, which may enhance antimicrobial activity of FQs even against FQ-resistant $S$. aureus. ${ }^{57,58}$

We acknowledge certain limitations in the present analysis based upon the study design. All isolates were obtained from the nonoperative eye, and no assessments were made of the degree of surface sterilization following application of either povidone-iodine or antibiotics. In addition, despite a high degree of sensitivity and specificity, oxacillin testing, as performed in the present study, ultimately remains a surrogate for detecting the mecA gene in the identification of resistant species of Staphylococcus ${ }^{59}$ Furthermore, the categorization of HCWs and non-HCWs based on a questionnaire may not have fully separated patients as potential carriers of nosocomial versus community-acquired strains of resistant organisms. However, given that the carrier rates were comparable between groups, it is unlikely that misclassification with respect to HCW status would have led to different conclusions. In order to further categorize the species isolated and better appreciate the potential risk these resistant isolates pose to patients, the susceptibility profiles against a full array of non- $\beta$-lactam antibiotics will be performed in a subsequent study.

In the present study, more than one-third of cataract surgery patients were colonized with methicillin-resistant Staphylococcus on their ocular or periocular surface. Given the rising rates of community-acquired methicillin-resistant Staphylococcus, history and clinical signs are no longer sufficient to predict which patients will be colonized with MRSA or MRSE. In fact, this study demonstrated that individuals who did not work in the health care industry were just as likely as HCWs to be colonized with methicillin-resistant Staphylococcus. For these reasons, we suggest that all patients undergoing cataract surgery should be presumed to be colonized with methicillin-resistant organisms. In addition, the likelihood of being colonized with MRSA or
MRSE increases directly with age, as does the incidence of endophthalmitis. We suggest that patient age is likely to become an important consideration in the design and implementation of prophylaxis regimens for all ophthalmic surgical procedures.

\section{Acknowledgment}

We thank Melissa Earl, MPH, for her statistical assistance with this manuscript.

\section{Disclosures}

This study was funded by Allergan, Inc., Irvine, CA. Drs F Bucci, F Price, and M Raizman are members of the Allergan Scientific Advisory Board. Drs R Olson, E Donnenfeld, K Solomon, U Devgan, W Trattler, S Dell, RB Wallace, M Callegan, and P McDonnell are consultants to Allergan, Inc. Ms T Conway and Drs R Schiffman and D Hollander are employees of Allergan, Inc. Ms H Brown has no financial and/or conflicting interests to disclose.

\section{References}

1. Bannerman TL, Rhoden DL, McAllister SK, Miller JM, Wilson LA. The source of coagulase-negative staphylococci in the Endophthalmitis Vitrectomy Study. A comparison of eyelid and intraocular isolates using pulsed-field gel electrophoresis. Arch Ophthalmol. 1997;115(3): 357-361.

2. Speaker MG, Milch FA, Shah MK, Eisner W, Kreiswirth BN. Role of external bacterial flora in the pathogenesis of acute postoperative endophthalmitis. Ophthalmology. 1991;98(5):639-649.

3. Ciulla TA, Starr MB, Masket S. Bacterial endophthalmitis prophylaxis for cataract surgery: an evidence-based update. Ophthalmology. 2002; 109(1):13-24.

4. Jensen MK, Fiscella RG, Moshirfar M, Mooney M. Third- and fourthgeneration fluoroquinolones: retrospective comparison of endophthalmitis after cataract surgery performed over 10 years. J Cataract Refract Surg. 2008;34(9):1460-1467.

5. Miller JJ, Scott IU, Flynn HW Jr, Smiddy WE, Newton J, Miller D. Acute-onset endophthalmitis after cataract surgery (2000-2004): incidence, clinical settings, and visual acuity outcomes after treatment. Am J Ophthalmol. 2005;139(6):983-987.

6. Moshirfar M, Feiz V, Vitale AT, Wegelin JA, Basavanthappa S, Wolsey DH. Endophthalmitis after uncomplicated cataract surgery with the use of fourth-generation fluoroquinolones: a retrospective observational case series. Ophthalmology. 2007;114(4):686-691.

7. Taban M, Behrens A, Newcomb RL, et al. Acute endophthalmitis following cataract surgery: a systematic review of the literature. Arch Ophthalmol. 2005;123(5):613-620.

8. West ES, Behrens A, McDonnell PJ, Tielsch JM, Schein OD. The incidence of endophthalmitis after cataract surgery among the US Medicare population increased between 1994 and 2001. Ophthalmology. 2005;112(8):1388-1394.

9. Lalwani GA, Flynn HW Jr, Scott IU, et al. Acute-onset endophthalmitis after clear corneal cataract surgery (1996-2005). Clinical features, causative organisms, and visual acuity outcomes. Ophthalmology. 2008; 115(3):473-476.

10. Miller DM, Vedula AS, Flynn HW Jr, et al. Endophthalmitis caused by staphylococcus epidermidis: in vitro antibiotic susceptibilities and clinical outcomes. Ophthalmic Surg Lasers Imaging. 2007;38(6): 446-451. 
11. Dickey JB, Thompson KD, Jay WM. Anterior chamber aspirate cultures after uncomplicated cataract surgery. Am J Ophthalmol. 1991;112(3): 278-282.

12. Mistlberger A, Ruckhofer J, Raithel E, et al. Anterior chamber contamination during cataract surgery with intraocular lens implantation. J Cataract Refract Surg. 1997;23(7):1064-1069.

13. Samad A, Solomon LD, Miller MA, Mendelson J. Anterior chamber contamination after uncomplicated phacoemulsification and intraocular lens implantation. Am J Ophthalmol. 1995;120(2):143-150.

14. Han DP, Wisniewski SR, Wilson LA, et al. Spectrum and susceptibilities of microbiologic isolates in the Endophthalmitis Vitrectomy Study. Am J Ophthalmol. 1996;122(1):1-17. Erratum appears in Am JOphthalmol. 1996;122(6):920.

15. Mollan SP, Gao A, Lockwood A, Durrani OM, Butler L. Postcataract endophthalmitis: incidence and microbial isolates in a United Kingdom region from 1996 through 2004. J Cataract Refract Surg. 2007;33(2): 265-268. Erratum appears in J Cataract Refract Surg. 2007;33(5):759.

16. Recchia FM, Busbee BG, Pearlman RB, Carvalho-Recchia CA, Ho AC. Changing trends in the microbiologic aspects of postcataract endophthalmitis. Arch Ophthalmol. 2005;123(3):341-346.

17. Deramo VA, Lai JC, Winokur J, Luchs J, Udell IJ. Visual outcome and bacterial sensitivity after methicillin-resistant Staphylococcus aureusassociated acute endophthalmitis. Am J Ophthalmol. 2008;145(3): 413-417

18. Barber M. Methicillin-resistant staphylococci. J Clin Pathol. 1961;14: 385-393.

19. Jevons MP, Coe AW, Parker MT. Methicillin resistance in staphylococci. Lancet. 1963;1(7287):904-907.

20. National Nosocomial Infections Surveillance (NNIS) System report, data summary from Jan 1990-May 1999, issued Jun 1999. Am J Infect Control. 1999;27(6):520-532.

21. Herold BC, Immergluck LC, Maranan MC, et al. Community-acquired methicillin-resistant Staphylococcus aureus in children with no identified predisposing risk. JAMA. 1998;279(8):593-598.

22. Saïd-Salim B, Mathema B, Kreiswirth BN. Community-acquired methicillin-resistant Staphylococcus aureus: an emerging pathogen. Infect Control Hosp Epidemiol. 2003;24(6):451-455.

23. Zetola N, Francis JS, Nuermberger EL, Bishai WR. Communityacquired methicillin-resistant Staphylococcus aureus: an emerging threat. Lancet Infect Dis. 2005;5(5):275-286.

24. Asbell PA, Sahm DF, Shaw M, Draghi DC, Brown NP. Increasing prevalence of methicillin resistance in serious ocular infections caused by Staphylococcus aureus in the United States: 2000 to 2005. J Cataract Refract Surg. 2008;34(5):814-818.

25. Blomquist PH. Methicillin-resistant Staphylococcus aureus infections of the eye and orbit (an American Ophthalmological Society thesis). Trans Am Ophthalmol Soc. 2006;104:322-345.

26. Cavuoto K, Zutshi D, Karp CL, Miller D, Feuer W. Update on bacterial conjunctivitis in South Florida. Ophthalmology. 2008;115(1):51-56.

27. Freidlin J, Acharya N, Lietman TM, Cevallos V, Whitcher JP, Margolis TP. Spectrum of eye disease caused by methicillin-resistant Staphylococcus aureus. Am J Ophthalmol. 2007;144(2):313-315.

28. Rudd JC, Moshirfar M. Methicillin-resistant Staphylococcus aureus keratitis after laser in situ keratomileusis. J Cataract Refract Surg. 2001;27(3):471-473.

29. Shanmuganathan VA, Armstrong M, Buller A, Tullo AB. External ocular infections due to methicillin-resistant Staphylococcus aureus (MRSA). Eye. 2005;19(3):284-291.

30. Solomon R, Donnenfeld ED, Perry HD, et al. Methicillin-resistant Staphylococcus aureus infectious keratitis following refractive surgery. Am J Ophthalmol. 2007;143(4):629-634.

31. Woodward M, Randleman JB. Bilateral methicillin-resistant Staphylococcus aureus keratitis after photorefractive keratectomy. J Cataract Refract Surg. 2007;33(2):316-319.

32. David MZ, Glikman D, Crawford SE, et al. What is communityassociated methicillin-resistant Staphylococcus aureus? J Infect Dis. 2008;197(9):1235-1243.
33. Naimi TS, LeDell KH, Como-Sabetti K, et al. Comparison of community- and health care-associated methicillin-resistant Staphylococcus aureus infection. JAMA. 2003;290(22):2976-2984.

34. Kato T, Hayasaka S. Methicillin-resistant Staphylococcus aureus and methicillin-resistant coagulase-negative staphylococci from conjunctivas of preoperative patients. Jpn J Ophthalmol. 1998;42(6): 461-465.

35. Bilen H, Ates O, Astam N, Uslu H, Akcay G, Baykal O. Conjunctival flora in patients with type 1 or type 2 diabetes mellitus. Adv Ther. 2007; 24(5):1028-1035.

36. Miño de Kaspar H, Koss MJ, He L, Blumenkranz MS, Ta CN. Antibiotic susceptibility of preoperative normal conjunctival bacteria. Am J Ophthalmol. 2005;139(4):730-733.

37. Park SH, Lim JA, Choi JS, Kim KA, Joo CK. The resistance patterns of normal ocular bacterial flora to 4 fluoroquinolone antibiotics. Cornea. 2009;28(1):68-72.

38. Boucher HW, Corey GR. Epidemiology of methicillin-resistant Staphylococcus aureus. Clin Infect Dis. 2008;46 Suppl 5: S344-S349.

39. Navarro MB, Huttner B, Harbarth S. Methicillin-resistant Staphylococcus aureus control in the 21st century: beyond the acute care hospital. Curr Opin Infect Dis. 2008;21(4):372-379.

40. Rutar T, Chambers HF, Crawford JB, et al. Ophthalmic manifestations of infections caused by the USA300 clone of community-associated methicillin-resistant Staphylococcus aureus. Ophthalmology. 2006; 113(8):1455-1462.

41. Fridkin SK, Hageman JC, Morrison M, et al. Methicillin-resistant Staphylococcus aureus disease in three communities. $N$ Engl J Med. 2005;352(14):1436-1444. Erratum appears in $N$ Eng $J$ Med. 2005; 352(22):2362.

42. Grubeck-Loebenstein B. Changes in the aging immune system. Biologicals. 1997;25(2):205-208.

43. Miller RA. The aging immune system: primer and prospectus. Science. 1996;273(5271):70-74.

44. Sunderkötter C, Kalden H, Luger TA. Aging and the skin immune system. Arch Dermatol. 1997;133(10):1256-1262.

45. Woog JJ. The incidence of symptomatic acquired lacrimal outflow obstruction among residents of Olmsted County, Minnesota, 1976-2000 (an American Ophthalmological Society thesis). Trans Am Ophthalmol Soc. 2007;105:649-666.

46. Hatch WV, Cernat G, Wong D, Devenyi R, Bell CM. Risk factors for acute endophthalmitis after cataract surgery: a population-based study. Ophthalmology. 2009;116(3):425-430.

47. Kowalski RP, Romanowski EG, Mah FS, Sasaki H, Fukuda M, Gordon YJ. A comparison of moxifloxacin and levofloxacin topical prophylaxis in a fluoroquinolone-resistant Staphylococcus aureus rabbit model. Jpn J Ophthalmol. 2008;52(3):211-216.

48. Chi CY, Wong WW, Fung CP, Yu KW, Liu CY. Epidemiology of community-acquired Staphylococcus aureus bacteremia. J Microbiol Immunol Infect. 2004;37(1):16-23.

49. Gorwitz RJ, Kruszon-Moran D, McAllister SK, et al. Changes in the prevalence of nasal colonization with Staphylococcus aureus in the United States, 2001-2004. J Infect Dis. 2008;197(9): 1226-1234.

50. Libert M, Elkholti M, Massaut J, Karmali R, Mascart G, Cherifi S. Risk factors for methicillin resistance and outcome of Staphylococcus aureus bloodstream infection in a Belgian University Hospital. J Hosp Infect. 2008;68(1):17-24.

51. Trilla A, Miro JM. Identifying high risk patients for Staphylococcus aureus infections: skin and soft tissue infections. J Chemother. 1995; 7 Suppl 3:37-43.

52. Warren DK, Guth RM, Coopersmith CM, Merz LR, Zack JE, Fraser VJ. Epidemiology of methicillin-resistant Staphylococcus aureus colonization in a surgical intensive care unit. Infect Control Hosp Epidemiol. 2006;27(10):1032-1040.

53. Speaker MG, Menikoff JA. Prophylaxis of endophthalmitis with topical povidone-iodine. Ophthalmology. 1991;98(12):1769-1775. 
54. Isenberg SJ, Apt L, Yoshimori R, Khwarg S. Chemical preparation of the eye in ophthalmic surgery. IV. Comparison of povidone-iodine on the conjunctiva with a prophylactic antibiotic. Arch Ophthalmol. 1985;103(9):1340-1342.

55. Miño de Kaspar H, Kreutzer TC, Aguirre-Romo I, et al. A prospective randomized study to determine the efficacy of preoperative topical levofloxacin in reducing conjunctival bacterial flora. Am J Ophthalmol. 2008;145(1):136-142.

56. Asbell PA, Colby KA, Deng S, et al. Ocular TRUST: nationwide antimicrobial susceptibility patterns in ocular isolates. Am J Ophthalmol. 2008;145(6):951-958.
57. Blondeau JM, Borsos S, Hesje CK. Antimicrobial efficacy of gatifloxacin and moxifloxacin with and without benzalkonium chloride compared with ciprofloxacin and levofloxacin against methicillinresistant Staphylococcus aureus. J Chemother. 2007;19(2):146-151.

58. Romanowski EG, Mah FS, Kowalski RP, Yates KA, Gordon YJ. Benzalkonium chloride enhances the antibacterial efficacy of gatifloxacin in an experimental rabbit model of intrastromal keratitis. $J$ Ocul Pharmacol Ther. 2008;24(4):380-384.

59. Velasco D, del Mar Tomas M, Cartelle M, et al. Evaluation of different methods for detecting methicillin (oxacillin) resistance in Staphylococcus aureus. J Antimicrob Chemother. 2005;55(3):379-382.
Clinical Ophthalmology

\section{Publish your work in this journal}

Clinical Ophthalmology is an international, peer-reviewed journal covering all subspecialties within ophthalmology. Key topics include: Optometry; Visual science; Pharmacology and drug therapy in eye diseases; Basic Sciences; Primary and Secondary eye care; Patient Safety and Quality of Care Improvements. This journal is indexed on

\section{Dovepress}

PubMed Central and CAS, and is the official journal of The Society of Clinical Ophthalmology (SCO). The manuscript management system is completely online and includes a very quick and fair peer-review system, which is all easy to use. Visit http://www.dovepress.com/ testimonials.php to read real quotes from published authors. 